\title{
Biohackers gear up for genome editing
}

\section{Amateurs are ready and able to try the CRISPR technique for rewriting genes.}

\section{BY HEIDI LEDFORD}

A complete lack of formal scientific training has not kept Johan Sosa from dabbling with one of the most powerful molecular-biology tools to come along in decades.

Sosa has already used CRISPR, a three-yearold technology that makes targeted modifications to DNA, in test-tube experiments. Next week, he hopes to try the method in yeast and, later, in the model plant Arabidopsis thaliana.

Hailed for its simplicity and versatility, CRISPR allows scientists to make specific changes to a gene's sequence more easily than ever before. Researchers have used CRISPR to edit genes in everything from bacteria to human embryos; the technique holds the potential to erase genetic defects from family pedigrees plagued by inherited disease, treat cancer in unprecedented ways or grow human organs in pigs. One researcher has even proposed modifying the elephant genome to produce a cold-adapted replica of the longextinct woolly mammoth.

Such feats are beyond the reach of do-ityourself (DIY) 'biohackers', a growing community of amateur biologists who often work in community laboratories, which typically charge a recurring fee for access to equipment and supplies. But CRISPR itself is not. Driven by an inventive spirit that inspires them to fiddle with yeast to alter the flavour of beer, build art installations out of bacteria or pursue serious basic-research questions, these amateurs cannot wait to try the technique.

"It's, like, the most amazing tool ever," says Andreas Stürmer, a biohacker and entrepreneur who lives in Dublin. "You could do it in your own home."

Sosa is an IT consultant from San Jose,

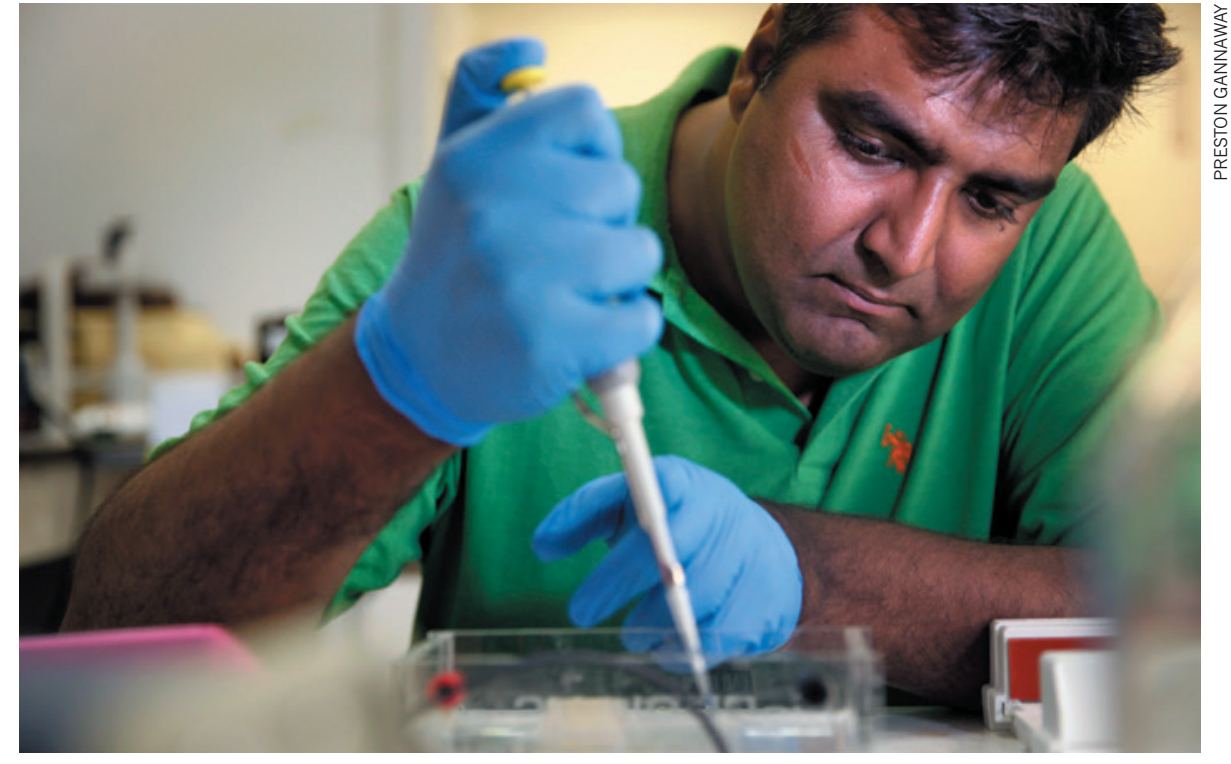

Biohackers such as Johan Sosa are exploring the creative potential of molecular biology.

California, who took up biohacking as a hobby about three years ago, when he decided that he would like to grow organs - or maybe other body parts - in the lab. At first, he had no idea how unrealistic that goal was. "I just thought you take a bunch of stem cells and add stuff to them," he says.

The challenge of manipulating living cells sank in as he began to read molecularbiology textbooks, attend seminars and teach himself laboratory techniques. He joined the BioCurious community lab in Sunnyvale, California.

Sosa is not quite sure what he will do with CRISPR once he has mastered it. He might participate in a group effort at BioCurious to engineer yeast to produce casein, a protein found in milk, as a step towards making vegan cheese. That could involve using CRISPR to learn how proteins are chemically modified in different types of yeast. "Now we have this ability to do what the major labs have been doing all this time," he says. "It's very exciting."

Artist Georg Tremmel, a research fellow in biological-data visualization at the University of Tokyo, has clear plans for CRISPR. He and his collaborators plan to 'de-engineer' genetically modified blue carnations sold in Japan by snipping out the inserted gene that turns the flower blue, thus reverting it to its 'natural', white state. They want audiences to ponder whether these doubly modified carnations should be deemed any different from unengineered plants with essentially the same genome.

So far, the hardest part of the project has not been using CRISPR, but growing the

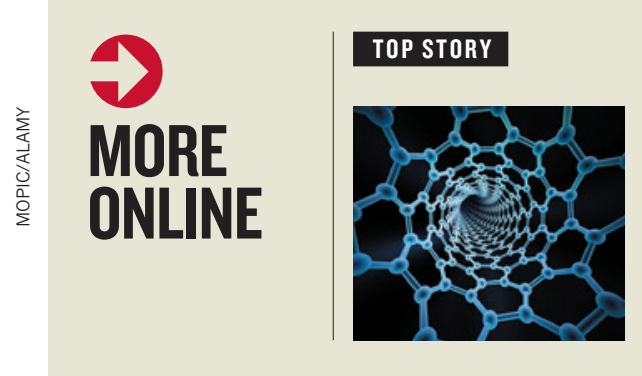

Carbon nanotubes that may act as insulin monitors go.nature.com/ z6xnxu

\section{MORE NEWS}

- Revised 'pebble-accretion' theory helps to explain how Jupiter and Saturn got their start in life go.nature. com/zk2pry

- Carbon-credit scheme linked to greenhouse-gas production go.nature. com/5lvvmg

\section{NATURE PODCAST}

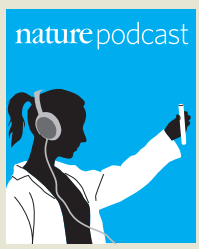

Squashing the hardest element, next-gen particle accelerators, and the scientific revolution nature. com/nature/podcast 
carnations in cell culture, Tremmel says. Another challenge will be getting permission to exhibit the work: although the blue carnations have been approved for sale in Japan, the de-engineered white carnations may need regulatory approval before they can be taken out of a laboratory.

In addition to its creative possibilities, CRISPR also poses potential for mischief. The US Federal Bureau of Investigation's Bioterrorism Protection Team has painstakingly forged relationships with the biohacker community over the past few years and regularly reminds its members to keep an eye out for suspicious activity. Those concerns may be unnecessary, says Todd Kuiken, who studies science policy at the Wilson Center, a think tank in Washington DC. Most biohackers have benign goals, he says, such as creating rainbow-coloured bacteria or brewing distinctive beer.

There is also a tendency to overestimate what a typical DIY biologist can do, Kuiken adds. Reagents such as enzymes and antibodies are expensive, molecularbiology experiments are time-consuming and equipment that professional scientists take for granted is often beyond the means of individuals or community labs. And most community labs insist that their members work only with organisms that require the lowest level of biosafety precautions, which leaves human cells and most pathogens off the menu. In some parts of Europe,

\section{ONATURE.COM} CRISPR: The good, the bad and the unknown nature.com/crispr genetic engineering is illegal outside of professional facilities. Given the constraints of a DIY lab, many hobbyists resort to CRISPR only when they need an extremely precise change to the genome, says Keoni Gandall, a 16-year-old biohacker and science-fair champion from Huntington Beach, California, who has been working with polymerase chain reaction machines and centrifuges at home for about three years. So far, Gandall has used CRISPR only while volunteering in a local university lab. "It's pretty good," he says.

One of the biggest fears surrounding CRISPR is that it could be used to create a genetic modification designed to spread through a population of organisms at an unnaturally fast rate. But Dan Wright, an environmental lawyer and DIY biohacker in Los Angeles, California, thinks that such a scenario is still beyond the ability of most amateurs. Constructing such a system would surpass the relatively simple tweaks that he and his colleagues are contemplating.

"It's too difficult," Wright says. "Just knocking out a gene in one plant is enough of a challenge for a biohacker space at this point." -

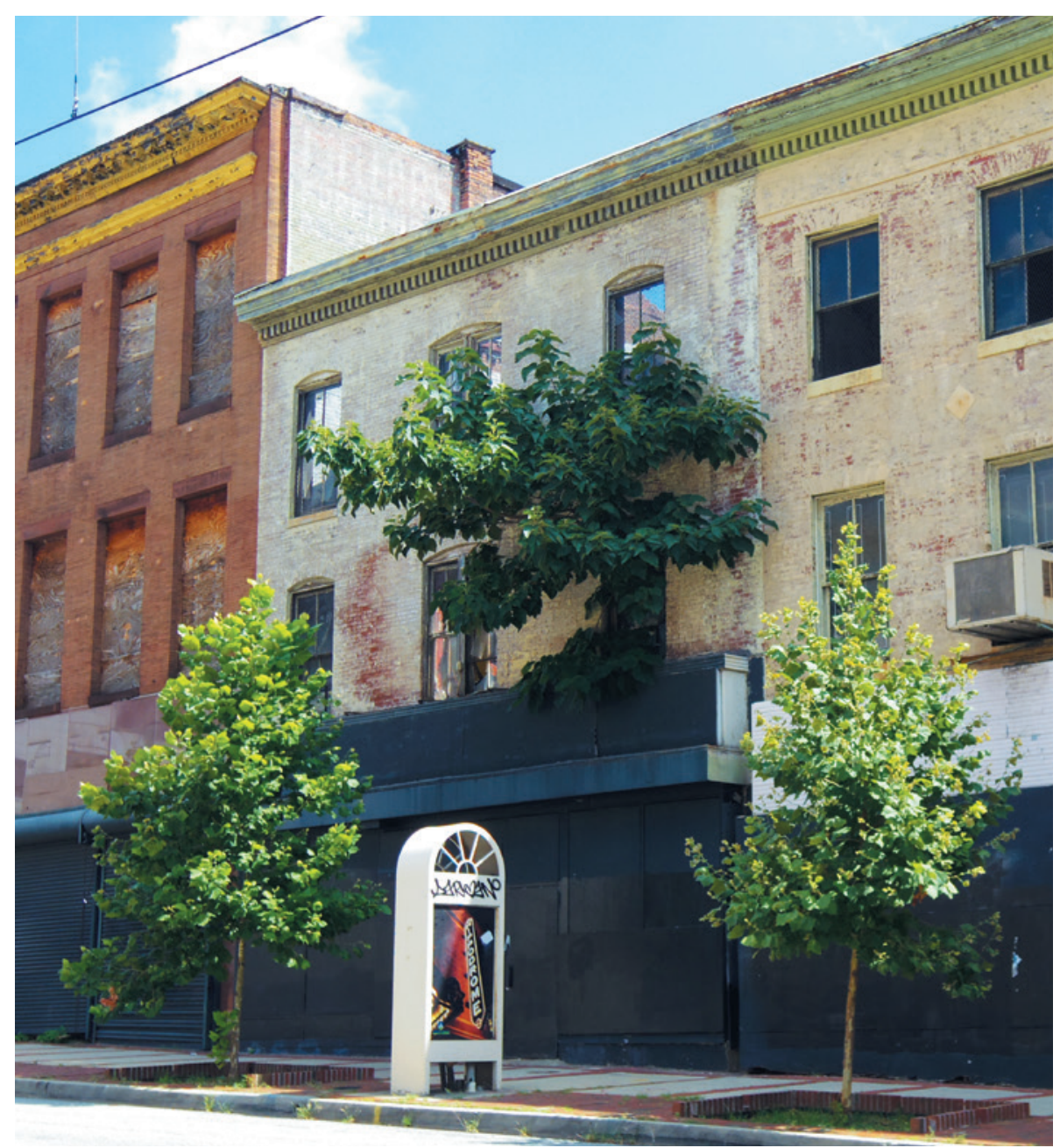

A tree grows in Baltimore: the city is at the heart of the burgeoning field of urban ecology.

ECOSYSTEMS

\section{Ecologists embrace their urban side}

\section{Climate change and the rise of cities have broadened what it means to study ecosystems.}

\section{BY DANIEL CRESSEY, BALTIMORE, MARYLAND}

A concrete megalith overshadowed by skyscrapers and surrounded by roads that roar with traffic, the convention centre in downtown Baltimore may seem an inappropriate setting for an ecology conference. But the resolutely urban backdrop for the annual meeting of the Ecological Society of America (ESA) is a fitting symbol of the growing acceptance of, and interest in, 'urban ecology' - the study of cities and the organisms that dwell in them as ecosystems.
"In the past 10 years, it's really become more mainstream. People's reactions have shifted from 'What's that?' or 'Why do you do that?' to 'Oh, cool,' says Laura Martin, a historian and urban ecologist at the Harvard University Center for the Environment in Cambridge, Massachusetts. She presented work at this year's centennial meeting (which ran on 9-14 August) showing that orange jewelweeds (Impatiens capensis) in Manhattan and other urban settings are evolving defences to incursions of certain deer that eat them (L. J. Martin et al. J. Ecol. 103, 243-249; 2015). Martin is part of a team that called at 